\title{
Numerical modeling of reducing total nitrogen through inflow from channels in Datong Lake, China
}

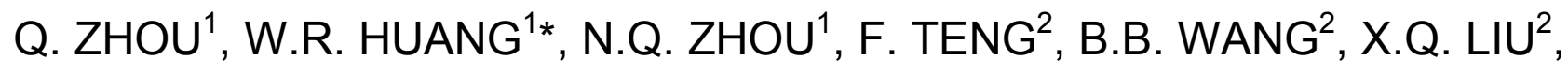 \\ S. XIE ${ }^{2}$, X.P. SHEN ${ }^{2}$ \\ ${ }^{1}$ Department of Hydraulic Engineering, Tongji University, Shanghai, China \\ ${ }^{2}$ Dongting Lake Water Resource Administration Bureau, Changsha, Hunan Province, China \\ *Corresponding author: whuang77@tongji.edu.cn
}

\begin{abstract}
KEYWORD: Datong Lake; Channel inflow; TN concentration; Numerical model
ABSTRACT: The total nitrogen (TN) concentration of Datong Lake has exceeded the standard concentration due to some artificial causes. Inflow from channels may be an effective method to help lower TN concentration and improve water quality. In this paper, a lake-channel network numerical model is set up for Datong Lake to simulate and study the effects of inflow from channels. The model simulation result shows that under the water level condition of $50 \%$ cumulative probability, TN concentration in Datong Lake can reduce to the concentration of III class in 80 days after inflow.
\end{abstract}

\section{INTRODUCTION}

Datong Lake is an inner lake located at the south bank of Yangtze River in Hunan Province, China. It is triangular in shape with a surface area of $85 \mathrm{~km}^{2}$. The lake was divided from Dongting Lake by man-made embankment in 1950, forming a polder area suitable for farming and fishery. It connects to the outside lakes and rivers such as Caowei River and East Dongting Lake by several channels and water gates.

Because of the relative closed environment, long time fish farming with chemical fertilizer and discharge of agricultural pollution, Datong Lake faces poor flow mobility and water quality problem. Total nitrogen (TN) is an important indicator in 'Environmental quality standards for surface water' issued by China Ministry of Environmental Protection, which reflects the nutritional status of water. According to the field observation results of Tsinghua University (2011) and relevant researches of Li et al. (2010) and Huang et al. (2013), TN concentration of Datong Lake is $1.97 \mathrm{mg} / \mathrm{L}$. It only meets the standard of $\mathrm{V}$ class, exceeding the standard concentration (III class) released by department of environmental protection in Hunan Province, which will lay negative influence on the development of agriculture and fishery in this area.

Inflow through channels from outside may be an effective method to reduce TN in Datong Lake to the standard concentration based on such situation, which has been studied by other researchers in other similar districts (Pei et al. 1998, Ma et al. 2007). To study the effects of channel inflow on reducing TN concentration in Datong Lake, a lake-channel network numerical model is set up to simulate TN concentration change after inflow from channels.

\section{DESCRIPTION OF HYDRODYNAMIC MODEL AND WATER QUALITY MODEL}

Hydrodynamic model DYNHYD5 and water quality model WASP7 are coupled and applied to Datong Lake. The models have a history of successful applications in other lakes, for example, Tufford \& Mckellar (1999) for Marion Lake, Gregory et al. (1990) for St. Clair Lake, Xu (2013) et al. for Gehu Lake and Shi et al. (2010) for Taihu Lake. They are also recommended by USEPA to be used to analyze and predict various water quality conditions. 
The basis equations of DYNHYD5 include equation of motion and equation of continuity. Equation of motion based on momentum conservation calculates velocity and flow while equation of continuity based on mass conservation calculates water head and volume.

Equation of motion is

$\frac{\partial U}{\partial t}=-U \frac{\partial U}{\partial x}+a_{g, \lambda}+a_{f}+a_{w, f}$

Equation of continuity is

$$
\frac{\partial A}{\partial t}=-\frac{\partial Q}{\partial x}
$$

The basis equation of WASP7 is mass balance equation:

$$
\frac{\partial C}{\partial t}=-\frac{\partial}{\partial x}\left(U_{x} C\right)+\frac{\partial}{\partial x}\left(E_{x} \frac{\partial C}{\partial x}\right)+S_{L}+S_{B}+S_{K}
$$

\section{MODEL SETUP AND VERIFICATION}

\section{Model setup}

The simulation area includes Datong Lake with main channels and rivers around it (Fig. 1). From west to east, these channels are Wuqi Channel, Caoyang Channel, and Saiyang River et al.

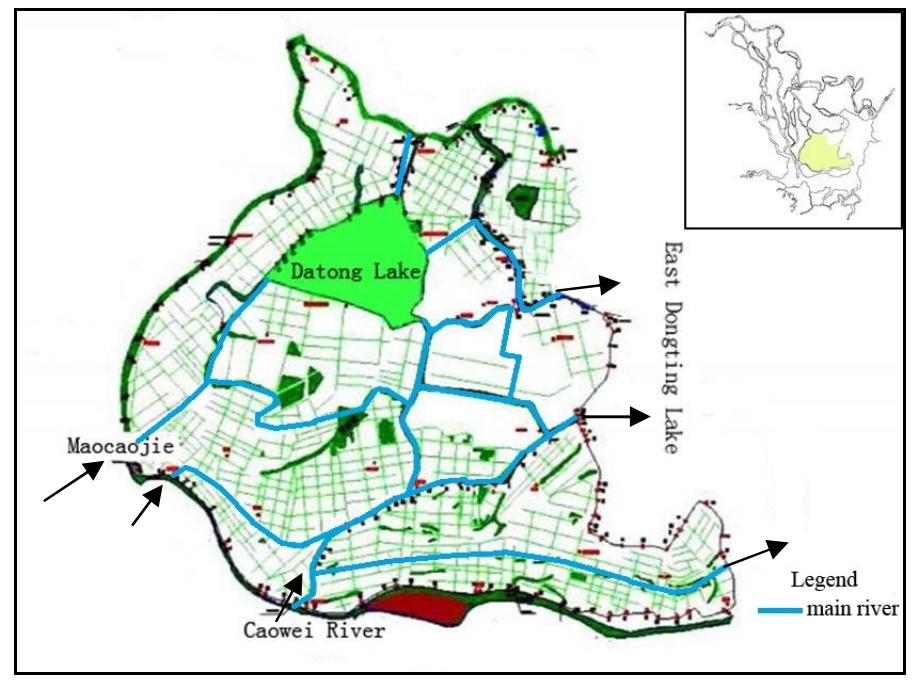

Figure 1. Study area of Datong Lake and inner-connected channel network.

A lake-channel network model has been set up for Datong Lake and main inner channels as shown in Figure 2. Six boundary points are set for the model, among which Maocaojie Gate, Caowei Gate and Huangmaozhou gate are three upper boundary points while Hexing Gate, Dadongkou Gate and Xiangdong Gate are three lower boundary points. The channels are divided into segments of $2 \sim 3 \mathrm{~km}$ long, with the length of segments being reduced where channel joints concentrate. Datong Lake is divided into five parts from west to east. 


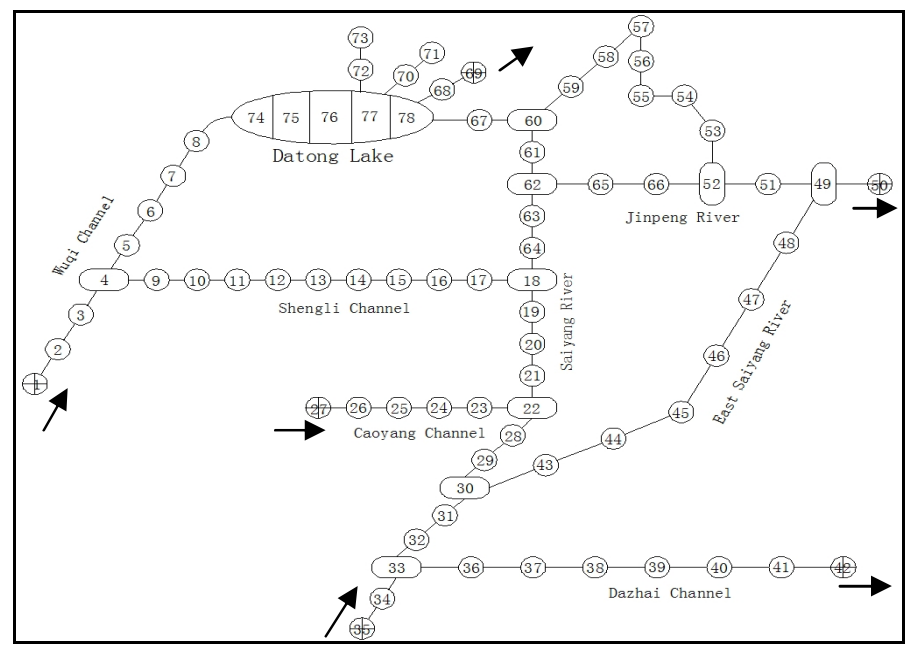

Figure 2. Lake-channel network model of simulation area.

\section{Model parameters}

Channel width, water depth and velocities are obtained by field observation. Channel lengths are measured on satellite map using ArcGIS. Owing to the lack of channel roughness data, the manning coefficients of different channels are set according to 'Fluid mechanics for hydraulic engineers'.

The diffusive coefficient of TN is set to $0.16 \mathrm{~m}^{2} / \mathrm{s}$ on the basis of user guide of WASP7 and research results of Peeters et al. (1996) and Kashefipour \& Falconer (2002). The decay coefficient of TN is set to 0.008/d in terms of the studies on adjacent Dongting Lake district (Tsinghua University 2011, China Institute of Water Resources and Hydropower Research 2011).

\section{Model verification}

It can be assumed from field observation that the flow in channels is steady. Theoretical inflow and outflow are calculated from measured data to be used as boundary flow condition. Measured velocities of four observation points are used to help modify the manning coefficient and verify the hydrodynamic model. The manning coefficients of main channels in the model are shown in Table 1.

Table 1. Manning coefficient of main channels.

\begin{tabular}{lllll}
\hline Channel & $\begin{array}{l}\text { Wuqi } \\
\text { Channel }\end{array}$ & $\begin{array}{l}\text { Saiyang } \\
\text { River }\end{array}$ & $\begin{array}{l}\text { Caoyang } \\
\text { Channel }\end{array}$ & $\begin{array}{l}\text { Jinpeng } \\
\text { River }\end{array}$ \\
\hline $\begin{array}{l}\text { Manning } \\
\text { Coefficient }\end{array}$ & 0.045 & 0.046 & 0.033 & 0.036 \\
\hline
\end{tabular}

A comparison of velocity simulated and that measured is listed in Table 2. As can be seen from the table, simulated velocities are close to measured values. The biggest relative error of them is $4.9 \%$ while the smallest is $2.0 \%$, indicating that the lake-channel model is able to simulate and predict flow distribution in the channel network.

Table 2. Comparison of simulated velocity and measured velocity.

\begin{tabular}{llll}
\hline $\begin{array}{l}\text { Observa- } \\
\text { tion points }\end{array}$ & $\begin{array}{l}\text { Measured } \\
\text { velocity }\end{array}$ & $\begin{array}{l}\text { Simulated } \\
\text { velocity }\end{array}$ & $\begin{array}{l}\text { Relative } \\
\text { Error }\end{array}$ \\
\cline { 2 - 3 } $\mathrm{m} / \mathrm{s}$ & $\mathrm{m} / \mathrm{s}$ & \\
\hline 1 & 0.10 & 0.1030 & $3.0 \%$ \\
2 & 0.10 & 0.0980 & $2.0 \%$ \\
3 & 0.05 & 0.0522 & $4.4 \%$ \\
4 & 0.07 & 0.0734 & $4.9 \%$ \\
\hline
\end{tabular}


According to the study of Peeters (1996), the effective range of diffusive coefficient in lake is from $0.02 \mathrm{~m}^{2} / \mathrm{s}$ to $0.3 \mathrm{~m}^{2} / \mathrm{s}$. A sensitivity test of model has been done under the condition that the diffusive coefficient is set to $0.02 \mathrm{~m}^{2} / \mathrm{s}$ and $0.3 \mathrm{~m}^{2} / \mathrm{s}$ respectively. The test result shows that $\mathrm{TN}$ concentration changes in the lake are similar in the case of two coefficient values. It can be inferred that diffusive coefficient in the range of $0.02 \mathrm{~m}^{2} / \mathrm{s}$ to $0.3 \mathrm{~m}^{2} / \mathrm{s}$ has little impact on TN concentration change. So the diffusive coefficient of the model is set to the median of the range: $0.16 \mathrm{~m}^{2} / \mathrm{s}$.

\section{MODEL SIMULATION AND RESULTS}

\section{Initial conditions}

The initial water level in Datong Lake and inner channels is set to a uniform value $25.28 \mathrm{~m}$, which is the mean value of decades' dry seasons in this area. The initial TN concentration is set to $1.97 \mathrm{mg} / \mathrm{L}$ according to field observation result and relevant researches.

\section{Boundary conditions}

The boundary water level range for inflow and outflow is decided by the water levels of inner area and outside river, the elevation of water gate bottom and the controlled water level of dike. According to the data of local hydraulic construction, the elevation of upper boundary gate bottom is $25.48 \mathrm{~m}$, higher than the initial inner water level. The elevation of lower boundary gate bottom is 23.98m. Outside the upper boundary is Caowei River with high water level while outside the lower boundary is East Dongting Lake with low water level. The flood control level of dike is $27.78 \mathrm{~m}$. Due to the need of flood control, the water level range allowed for inflow is from $25.48 \mathrm{~m}$ to $27.78 \mathrm{~m}$.

Continuous time series water level of typical year of Caowei River is used as upper boundary inflow water level condition. The method to choose typical year is to draw the cumulative probability curve of annual mean water level based on the everyday data from 1981 to 2012 firstly, and then select the year whose corresponding cumulative probability is $50 \%$ as the typical normal flow year, which reflects the average case. Through this method, the year of 1987 is chosen as the typical year.

The water level data of 1987 is picked out to draw the stage hydrograph of Caowei River. Due to the need of flood control, the time allowed for inflow is separated into two parts, the beginning several months and the ending ones. For the consistency and convenience of simulation, we combine two parts together to form a continuous period. The newly combined period is defined as the period for inflow, as is shown in Figure 3. The water level during the period for inflow is used as upper boundary water level condition. The lower boundary water level is set equal to the inner initial water level.

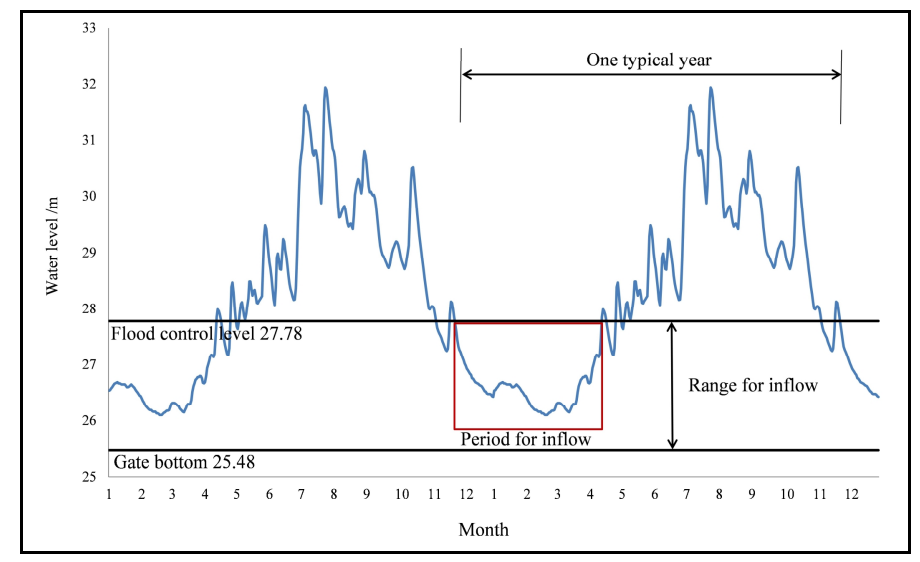

Figure 3. The newly defined period for inflow and stage hydrograph of Caowei River in 1987. 
The boundary TN concentration is set according to the water quality standard released by department of environmental protection in Hunan Province. Standard concentration values are listed in Table 3.

Table 3. Boundary TN concentration.

\begin{tabular}{llll}
\hline & Water gate & $\mathrm{TN}$ & Water \\
\cline { 3 - 4 } & $\mathrm{mg} / \mathrm{L}$ & $\begin{array}{l}\text { Quality } \\
\text { Class }\end{array}$ \\
\hline Upper & Maocaojie & 0.5 & II \\
boundary & Caowei & 1.0 & III \\
& Huangmaozhou & 1.0 & III \\
Lower & Hexing & & \\
Boundary & $\begin{array}{l}\text { Dadongkou } \\
\text { Hekou }\end{array}$ & 1.0 & III \\
\end{tabular}

*Water quality classification is based on 'Environmental quality standards for surface water' (China Ministry of Environmental Protection 2002)

\section{Simulation results}

Under the boundary water level condition of 1987, change of TN concentration in Datong Lake after water inflow is shown in Figure 4. It can be seen from the figure that TN concentration in Datong Lake takes 80 days to reduce to the standard (III class) totally. The time that different parts of the lake take is in the order of $1<2<3<4<5$. TN concentration of part 1 drops fastest and that of part 5 drops the most slowly.

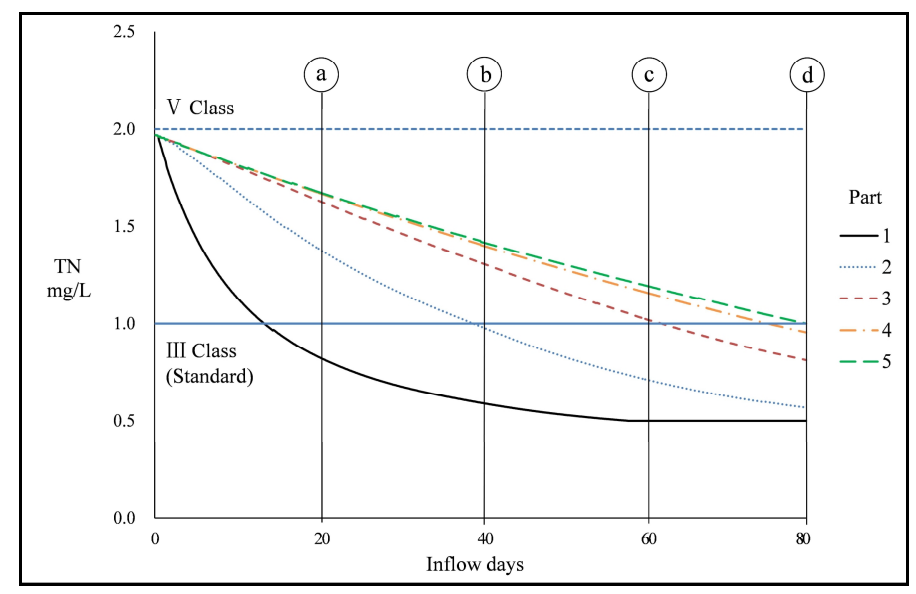

Figure 4. TN concentration change curve in Datong Lake.

Figure 5 shows the distribution of TN concentration in Datong Lake at different times corresponding to the time a, b, c, d in Figure 4. We can see from the figure that at time a (20 days after water inflow), TN concentration of part 1 has reduced to the standard while that of part 3, 4 and 5 is still at high level, with the concentration of part 4 and 5 quite close. At time b (40 days after water inflow), TN concentration of part 3, 4 and 5 has dropped a little. At time c (60 days after water inflow), TN concentration of part 3 nearly reduces to the standard and the concentration of part 4 and 5 has dropped a lot. At time d ( 80 days after water inflow), TN concentration of all parts has reduced to the standard and concentration differences of these parts has decreased a lot compared to the beginning. 


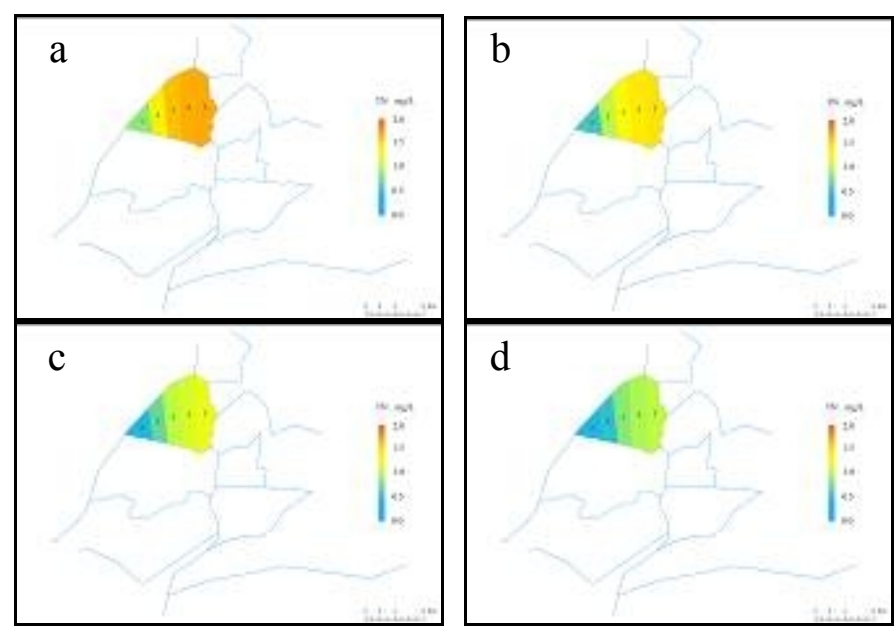

Figure 5. Distribution of TN concentration in Datong Lake at different time.

\section{CONCLUSION}

A lake-channel network numerical model has been applied to simulate TN concentration change in Datong Lake after water inflow from channels. It can be concluded from the simulation result that (1) inflow from channels can lower TN concentration of Datong Lake effectively if the concentration of Caowei River outside the dike meets the specified standard; (2) under the boundary water level condition of $50 \%$ cumulative probability, it takes 80 days for Datong Lake to reduce TN to the standard concentration of $1.0 \mathrm{~m} / \mathrm{L}$ totally; (3) different parts of Datong Lake takes different time to reduce $\mathrm{TN}$ concentration to the standard and the time needed decreases from west parts to east parts.

\section{REFERENCES}

[1] China Institute of Water Resources and Hydropower Research 2011. Effect study of Songzikou gate construction on water quality in Dongting Lake district. Beijing.

[2] China Ministry of Environmental Protection 2002. Environmental quality standards for surface water. Beijing.

[3] Gregory A. et al. 1990. Modeling the fate and transport of organic contaminants in Lake St. Clair. Journal of Great Lakes Research 16(2): 216-232.

[4] Huang D.Z. et al. 2013. Changes of Water Quality and Eutrophic State in Recent 20 Years of Dongting Lake. Research of Environmental Sciences 26(1): 27-33.

[5] Hunter R (ed.) 1988. Fluid mechanics for hydraulic engineers. New York: McGraw-Hill Book Company, inc.

[6] Kashefipour S.M. \& Falconer R.A. 2002. Longitudinal dispersion coefficients in natural channels. Water Research. 36: 1596-1608.

[7] Li D.L. et al. 2010. Distribution and risk evaluation of heavy metals in typical lakes in middle reaches of the Yangtze River-Taking the Datong Lake for example. Resources and Environment in the Yangtze Basin 19:182-189.

[8] $\mathrm{Ma} \mathrm{W}$. et al. 2007. Countermeasure of water diversion and regulation to improve the water environment of Taihu Lake and prediction of its effect. Resources and Enviro nment in the Yang tze Basin 16(1): 52-56.

[9] Peeters F. et al. 1996. Horizontal mixing in lakes. Journal of Geophysical Research/Oceans 8: 361-375.

[10] Pei H.P. et al. 1998. A phosphorus circulation dynamics model in the ecosystem for the west lake after drawing, Hangzhou. ACTA ECOLOGICA SINICA 18(6): 648-653.

[11] Shi T.C. et al. 2010. Regional management strategy integrated with WASP model on water quality for river-network plain located in Huzhou District, Taihu Lake Basin. Acta Scientiae Circumstantiae 30(3): 631-640. 
[12] Tsinghua University. 2011. Study on water environment change of Dongting Lake district after the Three Gorges Project. Beijing.

[13] Tuffird D.L. \& Mckellar H.N. 1999. Spatial and temporal hydrodynamic and water quality modeling analysis of a large reservoir on the South Carolina (USA) coastal plain. Ecological modeling 114(2): 137-173.

[14] Wool T.A. et al. 2008. Water Quality Analysis Simulation Program User's Guide. US Environment Protection Agency. Washington.

[15] Xu L. et al. 2013. A history evaluation modeling and forecastation of water quality in shallow lake. Water and Environmental Journal 27(4):514-523 